\title{
Yellow fever
}

INSERM

\section{Source}

INSERM. (1999). Orphanet: an online rare disease and orphan drug data base. Yellow fever. ORPHA:99829

Yellow fever (YF), caused by YF virus, is a zoonotic disease characterized by fever and constitutional symptoms, with the potential to progress to severe and fatal viral hemorrhagic fever with shock and multi-organ system failure. 